\title{
Expression levels of CXCR4 and CXCL12 in patients with rheumatoid arthritis and its correlation with disease activity
}

\author{
LIPING PENG*, NING ZHU*, JING MAO, LI HUANG, YAMENG YANG, \\ ZHENGJU ZHOU, LI WANG and BIN WU
}

\begin{abstract}
Department of Rheumatology and Immunology, First People's Hospital of Jingzhou, The First Affiliated Hospital of Yangtze University, Jingzhou, Hubei 434000, P.R. China
\end{abstract}

Received April 24, 2019; Accepted February 26, 2020

DOI: $10.3892 /$ etm. 2020.8950

\begin{abstract}
The present study aimed to investigate the expression levels of C-X-C motif chemokine receptor 4 (CXCR4) and CXC ligand 12 (CXCL12) in patients with rheumatoid arthritis (RA) and the correlation with disease activity. In total, 60 patients with RA were selected as the study group, comprising of 28 patients in active-stage and 32 patients in remission-stage. In addition, 60 patients with osteoarthritis were selected as the control group. Western blotting and ELISA were used to detect the expression of CXCR4 and CXCL12, respectively. The Spearman's correlation test was used to analyze correlations between CXCR4 and CXCL12, and erythrocyte sedimentation rate (ESR), C-reactive protein (CRP), disease activity score 28 (DAS28) scores and rheumatoid factor (RF). The present results suggested that CXCR4 and CXCL12 expression levels in the serum and joint synovial fluid of the study group were significantly higher compared with the control group $(\mathrm{P}<0.05)$. Moreover, CXCR4 and CXCL12 expression levels in the RA-active group were higher compared with the remission $(\mathrm{P}<0.05)$ and control groups $(\mathrm{P}<0.01)$. The Pearson test results suggested that the expression levels of CXCR4 and CXCL12 in the serum and joint synovial fluid of patients with RA had a positive correlation with the ESR, CRP, RF and DAS28 scores $(\mathrm{P}<0.05)$. CXCL12 and CXCR4 were highly expressed in the serum and joint synovial fluid of patients with RA, and these expression levels were positively correlated with ESR, CRP, RF and DAS28 scores. Therefore, these clinical parameters may be used as indicators to evaluate the disease activity of patients with RA.
\end{abstract}

Correspondence to: Dr Bin Wu, Department of Rheumatology and Immunology, First People's Hospital of Jingzhou, The First Affiliated Hospital of Yangtze University, 8 Hangkong Road, Jingzhou, Hubei 434000, P.R. China

E-mail: binglaw@163.com

*Contributed equally

Key words: rheumatoid arthritis, C-X-C motif chemokine receptor 4 , C-X-C motif chemokine ligand 12, disease activity, diagnostic indicators

\section{Introduction}

Rheumatoid arthritis (RA) is a common systemic autoimmune disease (1). The primary pathological manifestations of RA are chronic synovium inflammation and pannus formation, which can lead to swelling and deformities in the joints of patients (2). These symptoms can later lead to disability, which may cause a loss of work time, which can create a burden on society and the families of patients (3). The pathogenesis of RA is complex, involving many types of cells, including macrophages, $\mathrm{T}$ and $\mathrm{B}$ cells, fibroblasts, chondrocytes and dendritic cells (4). Despite study into the role of many genes and mechanisms underlying the development of RA, there is still no clear predisposing factor (5-7).

Chemokines are small protein cytokines, and their main function is to induce leukocytes aggregation to form inflammatory lesions, via directional migration, for participation in the inflammatory response (8). Previous studies have demonstrated that many chemokines are highly expressed in the joint synovial fluid or peripheral blood of patients with RA, which suggests that chemokines may be associated with RA pathogenesis $(9,10)$.

C-X-C motif chemokine ligand 12 (CXCL12) is mainly produced by stromal cells and is a key factor for the activation and migration of inflammatory cells to synovial tissues (11). CXC receptor 4 (CXCR4) is a natural receptor of CXCL12 (12). The chemokine CXCL12 can participate in the immune response to RA by mediating the migration and activation of $\mathrm{T}$ and $\mathrm{B}$ cells in immune cells (13). CXCL12 can also be secreted and produced by joint synovial cells, while CXCR4 can be expressed on the surface of articular chondrocytes $(14,15)$. The activation of CXCR4 and CXCL12 can induce the secretion of a variety of inflammatory factors from articular chondrocytes, leading to apoptosis and destruction of chondrocytes $(16,17)$. Previous studies have demonstrated that CXCR4 and CXCL12 together can serve an important role in lupus erythematosus (18-20). These aforementioned studies indicated that CXCR4 and CXCL12 are closely associated with autoimmune diseases.

Although previous studies have indicated that the expression of CXCL12 in the joint synovial membranes was significantly higher in the patients with RA compared with healthy controls (21), there are relatively few studies on the 
relationship between CXCR4 and CXCL12, and disease activity in patients with RA. Therefore, the present study investigated the expression levels of CXCR4 and CXCL12 in the serum and joint synovial fluid of patients with RA, and correlation analyses was performed to examine this data with clinical indicators. In addition, the present study investigated the roles of CXCR4 and CXCL12 in the occurrence and development of RA, and the relationship between CXCR4, CXCL12 and disease activity, to identify accurate evaluation indicators for use in patients with RA.

\section{Materials and methods}

Patient data. Using a random number table method, 60 patients (male patients, 34; female patients, 26) with RA were recruited and randomly selected as the study group from the Rheumatology and Immunology Department of First People's Hospital of Jingzhou from January 1 to December 31, 2018. The age distribution was 32-60 years old. The average age of all patients was $54.31 \pm 5.89$ years. Another 60 patients (male patients, 32; female patients, 28) with osteoarthritis, recruited from The First People's Hospital of Jingzhou hospital were selected as the control group.

Patients were selected based on inclusion and exclusion criteria. Patients who met the RA diagnostic criteria revised by The American College of Rheumatology in 1987 (22) were included in the study group, and patients who met the guidelines on management of osteoarthritis of the hand, hip and knee by the American College of Rheumatology (23) were included in the control group. Patients were excluded if they had any joint infection, severe liver or kidney dysfunction, cognitive or communication disorders, other autoimmune diseases or malignant tumors, or those who declined to participle. All patients agreed to participate in the experiment and signed an informed consent agreement. This experiment has been approved by the Hospital Ethics Committee of First People's Hospital of Jingzhou.

Specimen extraction. A total of $5 \mathrm{ml}$ fasting venous blood was obtained from all patients and centrifuged at $1,500 \mathrm{x} g$ for $10 \mathrm{~min}$ at $4^{\circ} \mathrm{C}$. The serum was collected following centrifugation $\left(1,500 \mathrm{x}\right.$ g for $10 \mathrm{~min}$ at $\left.4^{\circ} \mathrm{C}\right)$ and stored at $-80^{\circ} \mathrm{C}$. A total of $500 \mu \mathrm{l}$ joint fluid specimens were collected by outpatient joint punctures or knee joint surgery, and stored at $-80^{\circ} \mathrm{C}$ for subsequent analysis. Western blotting (WB) and ELISA were used to detect the expression levels of CXCR4 and CXCL12, respectively, in serum and joint fluid.

Detection of CXCR4 expression level using WB. $200 \mu 1$ Radioimmunoprecipitation assay buffer (Cell Signaling Technology, Inc.) was added to the serum and joint fluid specimens collected from patients. The cells were lysed and the total protein of each group was collected. BCA assays were used to determine the protein concentration. After collection, the protein was boiled in water for $8 \mathrm{~min}$ at $100^{\circ} \mathrm{C}$. A total of $20 \mu \mathrm{g}$ protein was loaded into the 10\% SDS-PAGE gel and run at $140 \mathrm{~V}$ for $2 \mathrm{~h}$. Subsequently, the protein was transferred to a PVDF membrane at $300 \mathrm{~mA}$ for $2 \mathrm{~h}$, and PVDF membrane was blocked with 5\% skimmed milk powder for $2 \mathrm{~h}$ at room temperature. The membranes were probed with the primary antibody targeting CXCR4 (1:1,000; Abcam; cat. no. ab227767) incubated overnight at $4^{\circ} \mathrm{C}$. The antibody GAPDH (1:500; Wuhan Fine Biotech Co., Ltd.; cat. no. FNab03342) was added and incubated overnight at $4^{\circ} \mathrm{C}$, then the membrane was probed with horseradish peroxidase (HRP)-labeled goat anti-rabbit secondary antibodies (1:5,000; Abcam; cat. no. ab97080) at room temperature for $2 \mathrm{~h}$. Subsequently, an enhanced chemiluminescence (ECL) developer (Invitrogen; Thermo Fisher Scientific, Inc.) was used to develop the protein bands. Filter paper was used to absorb excess liquid from the film and protein bands were developed for film-imaged using ECL. The protein bands were scanned and analyzed using Quantity One software (v4.6.6; Bio-Rad Laboratories, Inc.), where the relative expression level of the protein $=$ the gray value of the target protein band/the grey value of the GAPDH protein band.

Detection of CXCL12 expression in serum and joint fluid of patients using ELISA. The ELISA kit was purchased from Quanzhou Ruixin Biotechnology Co., Ltd. (cat. no. 13236). A total of $50 \mu \mathrm{l}$ of the diluted standard and samples were added into each reaction well, followed by $50 \mu \mathrm{l}$ biotin-labeled antibodies (all provided as part of the aforementioned kit). These samples were incubated at $37^{\circ} \mathrm{C}$ for $1 \mathrm{~h}$ and then washed using the wash buffer, 4 times for 5 min each time. Streptomycin-HRP conjugate from the aforementioned kit was added and incubated for $30 \mathrm{~min}$ at room temperature. Subsequently, a total of $50 \mu \mathrm{l}$ substrates provided by the aforementioned kit were added and incubated for $10 \mathrm{~min}$ at $37^{\circ} \mathrm{C}$. Subsequently, $50 \mu \mathrm{l}$ terminating solution, provided by the aforementioned kit, was added to each well and the OD values were measured at $450 \mathrm{~nm}$.

Detection of routine detection indexes in patients with $R A$. The erythrocyte sedimentation rate (ESR) from the patients with RA was detected using the Westergren's method (24) using an automatic erythrocyte sedimentation rate tester (Plyson cat. no. LBY-XC40B). C-reactive protein (CRP) and the rheumatoid factor (RF) were detected using rate scatter nephelometry (25) using an IMMAGE rate scattering turbidity analyzer (UniCel DxC800; Beckman Coulter, Inc.).

Outcome measures. The outcome measures were as follows: i) The levels of CXCR4 and CXCL12 in serum and joint fluid were compared between the study and control groups; ii) patients with RA were divided based on their disease activity score 28 (DAS28) scores (13) into the remission group ( 28 cases; $\leq 2.6$ points) and the active group (32 cases; $>2.6$ points), which were evaluated from four aspects, including the number of tender joints, the number of swollen joints and the erythrocyte sedimentation rate. DAS28 values range from 2.0-10.0 (13). A DAS28 <2.6 is interpreted as 'remission'; and iii) CXCR4 and CXCL12 expression levels in the serum and joint fluid of patients were compared. Correlations were analyzed between CXCR4 and CXCL12 expression levels, and ESR, CRP, DAS28 scores and RF in patients with RA.

Statistical analysis. SPSS 18.0 statistical software (SPSS Inc.) was used to analyze the experimental data. Data are presented as the mean \pm standard deviation. A $\chi^{2}$ test was used to analyze categorical data. An independent t-test was used for comparison between two groups. One-way ANOVA 


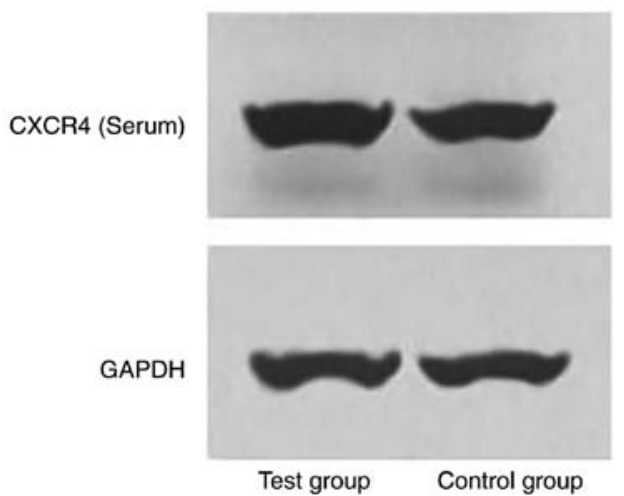

Figure 1. Western blotting results of CXCR4 expression levels in the study and control groups. Protein expression levels of CXCR4 in cells isolated from the serum of the study group were compared with the control group. CXCR4, C-X-C motif chemokine receptor 4.

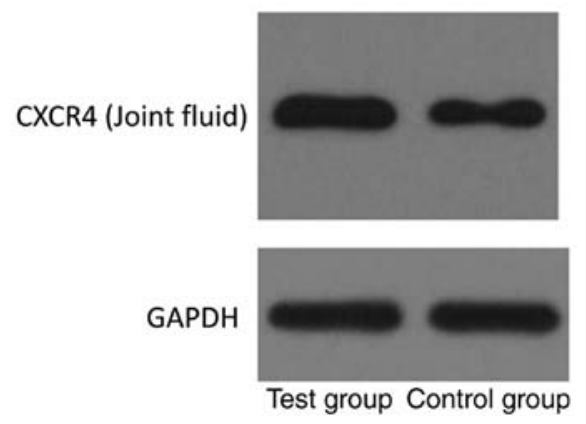

Figure 2. Western blotting results of CXCR4 expression levels in the study and control groups. Protein expression levels of CXCR4 in the cells isolated from the joint fluid of the study group compared with the control group. CXCR4, C-X-C motif chemokine receptor 4.

with a post-hoc LSD test was used for comparison among three groups. Spearman's correlation was used to analyze the correlation between CXCR4 and CXCL12 expression levels. The figures in this study were drawn using Graph Pad Prism 6 software (GraphPad Software, Inc.). $\mathrm{P}<0.05$ was considered to indicate a statistically significant difference.

\section{Results}

Patient data. There were no significant differences between sex, age or body mass index in the two groups (Table I).

CXCR4 and CXCL12 expression levels among the study and control groups. The serum CXCR4 expression levels of the study group were 5.12 \pm 1.04 and $3.62 \pm 0.54$, and the serum

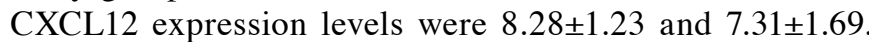
The joint fluid CXCR4 expression levels of the control group were $3.05 \pm 1.11$ and $2.13 \pm 0.63$, and the joint fluid CXCL12 expression levels were $5.14 \pm 1.12$ and $4.54 \pm 1.25$. The present results suggested that CXCR4 and CXCL12 expression levels in the serum and articular fluid of the study group were significantly higher compared with the control group $(\mathrm{P}<0.05$; Tables II and III; Figs. 1 and 2).

CXCR4 and CXCL12 expression levels among the RA, remission and control groups. The serum CXCR4 expression levels

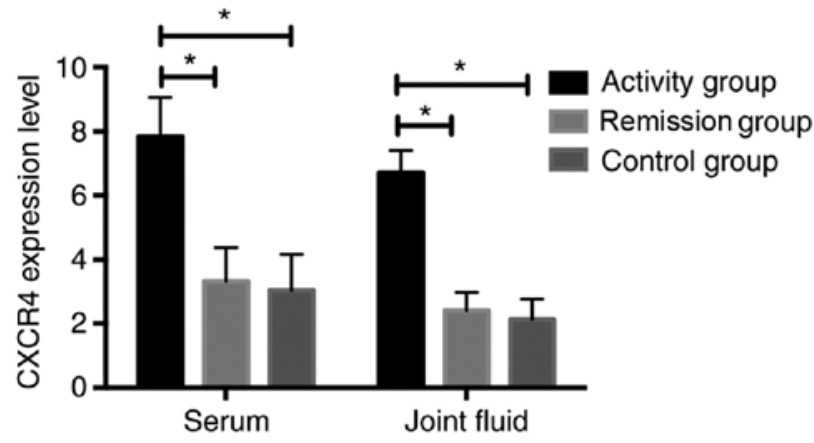

Figure 3. CXCR4 expression levels in the serum and joint fluid of the three patient groups. The expression level of CXCR4 in the RA-active group was higher compared with both the remission and control groups. There was no significant difference in the expression level of CXCR4 between the RA-remission and control groups. ${ }^{*} \mathrm{P}<0.05$. CXCR4, $\mathrm{C}-\mathrm{X}-\mathrm{C}$ motif chemokine receptor 4; RA, rheumatoid arthritis.

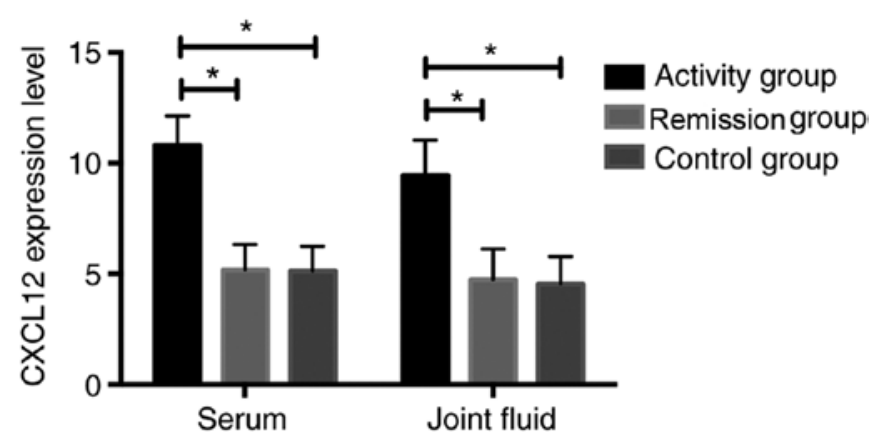

Figure 4. CXCL12 expression levels in the serum and joint fluid of the three patient groups. The expression level of CXCL12 in the RA-active group was higher compared with both the remission and control groups. There was no significant difference in the expression level of CXCL12 between the RA-remission and control groups. ${ }^{*} \mathrm{P}<0.05$. CXCL12, C-X-C motif chemokine ligand 12; RA, rheumatoid arthritis.

of the RA-active group were $7.85 \pm 1.21$ and $6.71 \pm 0.69$, and the serum CXCL12 expression levels were $10.82 \pm 1.33$ and 9.46 \pm 1.59 . CXCR4 expression levels of the RA-remission group were $3.33 \pm 1.05$ and $2.41 \pm 0.57$, and CXCL12 expression levels were $5.18 \pm 1.15$ and $4.74 \pm 1.39$. The joint fluid CXCR4 expression levels of the control group were $3.05 \pm 1.11$ and $2.13 \pm 0.63$, and the joint fluid CXCL12 expression levels were $5.14 \pm 1.12$ and $4.54 \pm 1.25$. Therefore, the present results suggested that the expression levels of CXCR4 and CXCL12 in the RA-active group were significantly higher compared with the RA-remission $(\mathrm{P}<0.05)$ and control groups $(\mathrm{P}<0.05$; Tables IV and V; Figs. 3 and 4).

Correlations between CXCR4 and CXCL12 expression levels and ESR, CRP, RF and DAS28 scores. The expression levels of CXCR4 and CXCL12 had a positive correlation with the ESR, CRP, RF and DAS28 scores (data not shown) of patients with RA (P<0.05; Tables VI and VII; Figs. 5-8).

Correlation between the expression of CXCR4 and CXCL12 with disease activity. Compared with the RA-active group, the expression of CXCR4 and CXCL12 in the serum of the RA remission group was significantly lower. Therefore, the present results suggested that the expression levels of CXCR4 
Table I. Patient characteristics.

\begin{tabular}{|c|c|c|c|c|}
\hline Characteristic & $\begin{array}{c}\text { Study group } \\
\mathrm{N}=60(\%)\end{array}$ & $\begin{array}{c}\text { Control group } \\
\mathrm{N}=60(\%)\end{array}$ & $\chi^{2 / t}$ & $\mathrm{P}$-value \\
\hline Sex & & & 0.090 & 0.764 \\
\hline Male & $34(56.67)$ & $32(53.33)$ & & \\
\hline Female & $26(43.33)$ & $28(46.67)$ & & \\
\hline Age & & & 0.022 & 0.882 \\
\hline$\geq 54$ & $31(51.67)$ & $30(50.00)$ & & \\
\hline$<54$ & $29(48.33)$ & $30(50.00)$ & & \\
\hline $\mathrm{BMI}, \mathrm{kg} / \mathrm{m}^{2}$ & & & 0.023 & 0.881 \\
\hline$\leq 22$ & $27(45.00)$ & $26(43.33)$ & & \\
\hline$>22$ & $33(55.00)$ & $34(56.67)$ & & \\
\hline Smoking & & & 1.808 & 0.179 \\
\hline No & $39(65.00)$ & $38(63.33)$ & & \\
\hline Yes & $21(35.00)$ & $22(36.67)$ & & \\
\hline Drinking volume, $\mathrm{ml}$ & & & 0.023 & 0.879 \\
\hline$<70$ & $37(61.67)$ & $36(60.00)$ & & \\
\hline$\geq 70$ & $23(38.33)$ & $14(40.00)$ & & \\
\hline \multicolumn{5}{|l|}{ Coagulation function } \\
\hline APTT, sec & $28.23 \pm 1.35$ & $28.19 \pm 1.41$ & 0.131 & 0.896 \\
\hline PT, sec & $11.31 \pm 1.15$ & $11.29 \pm 1.14$ & 0.078 & 0.938 \\
\hline FIB, $g / 1$ & $3.16 \pm 0.21$ & $3.19 \pm 0.19$ & 0.659 & 0.512 \\
\hline \multicolumn{5}{|c|}{ Renal function index $(\mu \mathrm{mol} / \mathrm{l})$} \\
\hline Creatinine & $57.63 \pm 4.45$ & $58.01 \pm 4.52$ & 0.280 & 0.705 \\
\hline Urea & $5.29 \pm 0.45$ & $5.31 \pm 0.57$ & 0.182 & 0.856 \\
\hline Uric acid & $291.34 \pm 11.35$ & $293.14 \pm 11.45$ & 0.707 & 0.481 \\
\hline
\end{tabular}

APTT, activated partial thromboplastin time; BMI, body mass index; FIB, fibrinogen; PT, prothrombin time.

Table II. CXCR4 expression levels in the serum and joint fluid of the study and control groups.

\begin{tabular}{lcccc}
\hline Factor & $\begin{array}{c}\text { Study group } \\
\mathrm{N}=60\end{array}$ & $\begin{array}{c}\text { Control group } \\
\mathrm{N}=60\end{array}$ & $\mathrm{t}$ & P-value \\
\hline Serum & $3.12 \pm 1.04$ & $3.05 \pm 1.11$ & 8.704 & $<0.001$ \\
Joint fluid & $3.62 \pm 0.54$ & $2.13 \pm 0.63$ & 11.67 & $<0.001$ \\
\hline
\end{tabular}

CXCR4, C-X-C motif chemokine receptor 4.

and CXCL12 were positively correlated with the changes in RA disease activity (CXCR4, $\mathrm{r}=0.858, \mathrm{P}<0.001$; CXCL12, r=0.864, P<0.001; Fig. 9).

\section{Discussion}

RA is a chronic systemic immune disease and its pathogenesis has yet to be elucidated, but abnormal immunity is considered to contribute to its development (26). Previous studies have demonstrated that over the course of RA, inflammatory cells migrate from peripheral blood to synovial tissues and secrete a variety of inflammatory factors, resulting in the destruction
Table III. CXCL12 expression levels in the serum and joint fluid of the study and control groups.

\begin{tabular}{lcccc}
\hline Factor & $\begin{array}{c}\text { Study group } \\
\mathrm{N}=60\end{array}$ & $\begin{array}{c}\text { Control group } \\
\mathrm{N}=60\end{array}$ & $\mathrm{t}$ & P-value \\
\hline Serum & $8.28 \pm 1.23$ & $5.14 \pm 1.12$ & 11.75 & $<0.001$ \\
Joint fluid & $7.31 \pm 1.69$ & $4.54 \pm 1.25$ & 7.947 & $<0.001$
\end{tabular}

CXCL12, C-X-C motif chemokine ligand 12.

of the synovial membrane $(27,28)$. Chemokines serve an important role in the infiltration and migration of inflammatory cells (29). CXCL12 is the only chemokine that binds to the receptor CXCR4 (30). CXCL12 and CXCR4 promote the migration of monocytes and $\mathrm{T}$ lymphocytes, and serve an important role in the process of inflammation (31). Previous studies have indicated that the expression levels of CXCL12 in the synovial tissue and joint fluid of patients with RA was increased, and that CXCR4 expression was also significantly increased in T lymphocytes (32-34).

CXCL12 can promote the secretion of matrix metalloproteins (MMPs) via chondrocytes, including MMP-1 and 

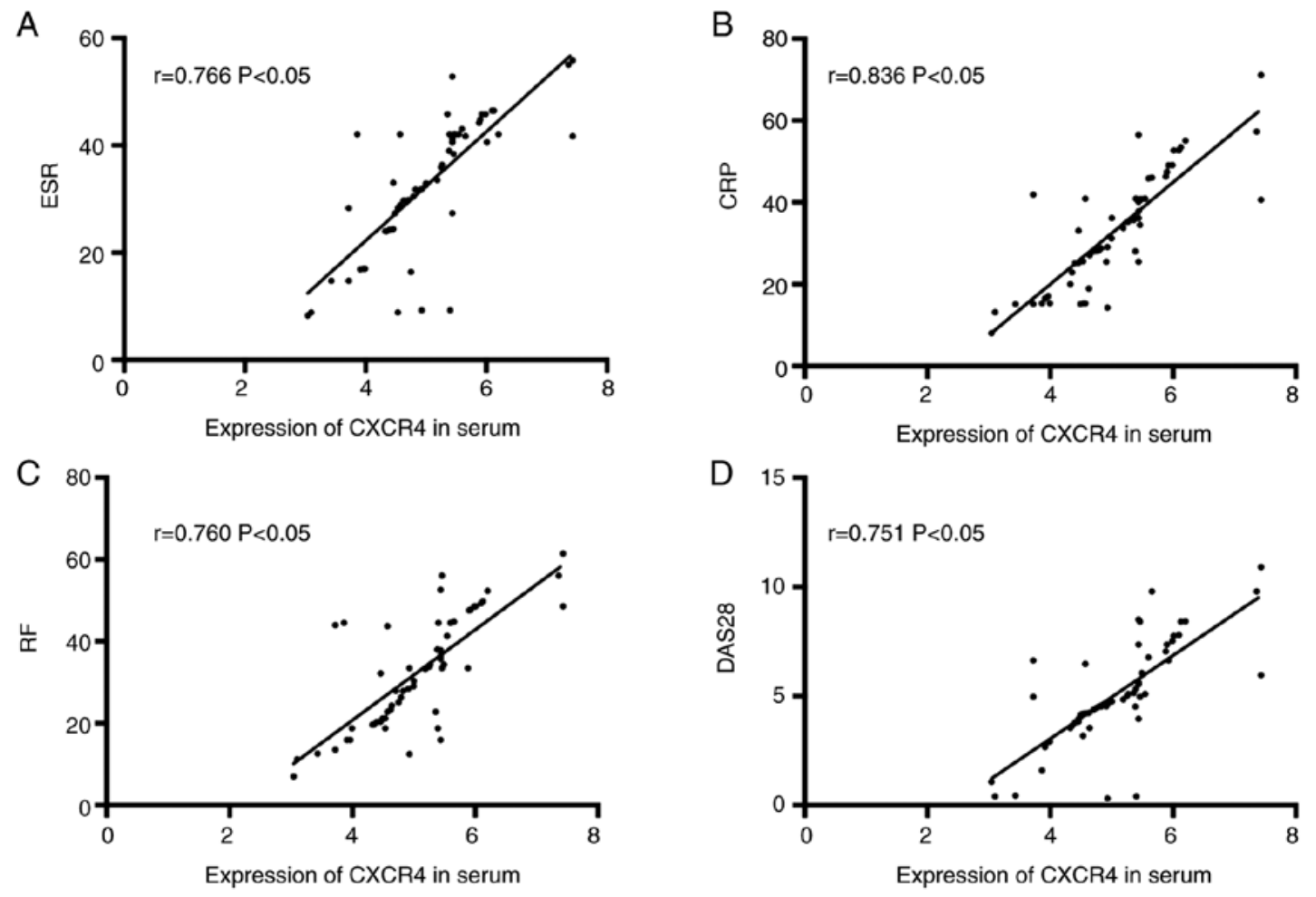

Figure 5. Correlations between serum CXCR4 expression and the ESR, CRP, RF and DAS28 scores of patients with RA. CXCR4 expression in the serum of patients with RA had a strong positive correlation with (A) ESR, (B) CRP, (C) RF and (D) DAS28 scores. CXCR4, C-X-C motif chemokine receptor 4; RA, rheumatoid arthritis; ESR, sedimentation rate; CRP, C-reactive protein; RF, rheumatoid factor; DAS28, disease activity score.
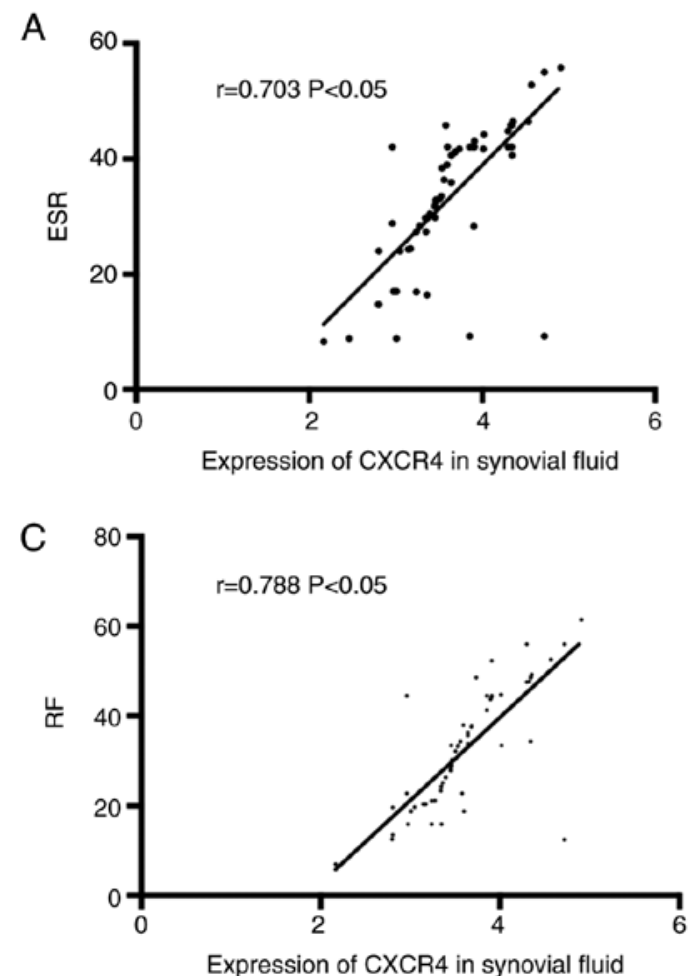
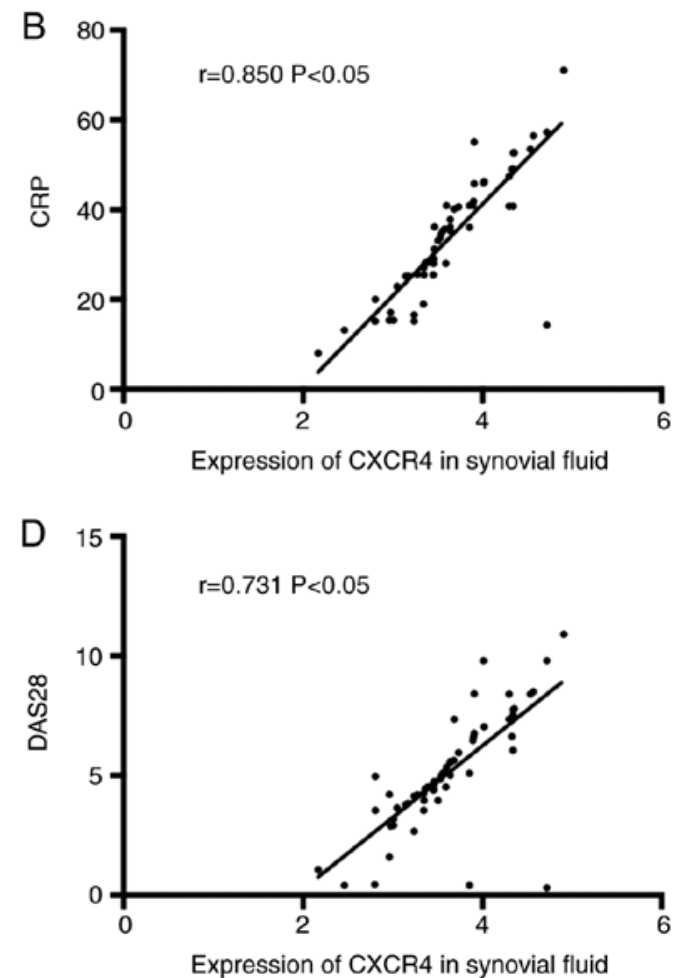

Figure 6. Correlations between joint fluid CXCR4 expression and the ESR, CRP, RF and DAS28 scores of patients with RA. CXCR4 expression in the joint fluid of patients with RA was had a strong positive correlation with (A) ESR, (B) CRP, (C) RF and (D) DAS28 scores. CXCR4, C-X-C motif chemokine receptor 4; RA, rheumatoid arthritis; ESR, sedimentation rate; CRP, C-reactive protein; RF, rheumatoid factor; DAS28, disease activity score.

MMP-13 (35). CXCR4 receptor antagonists have been used to reduce the expression levels of MMP-1 and MMP-13 in synovial fluid in patients with RA (36). In addition, CXCL12 and CXCR4 can further induce injury of the articular cartilage 

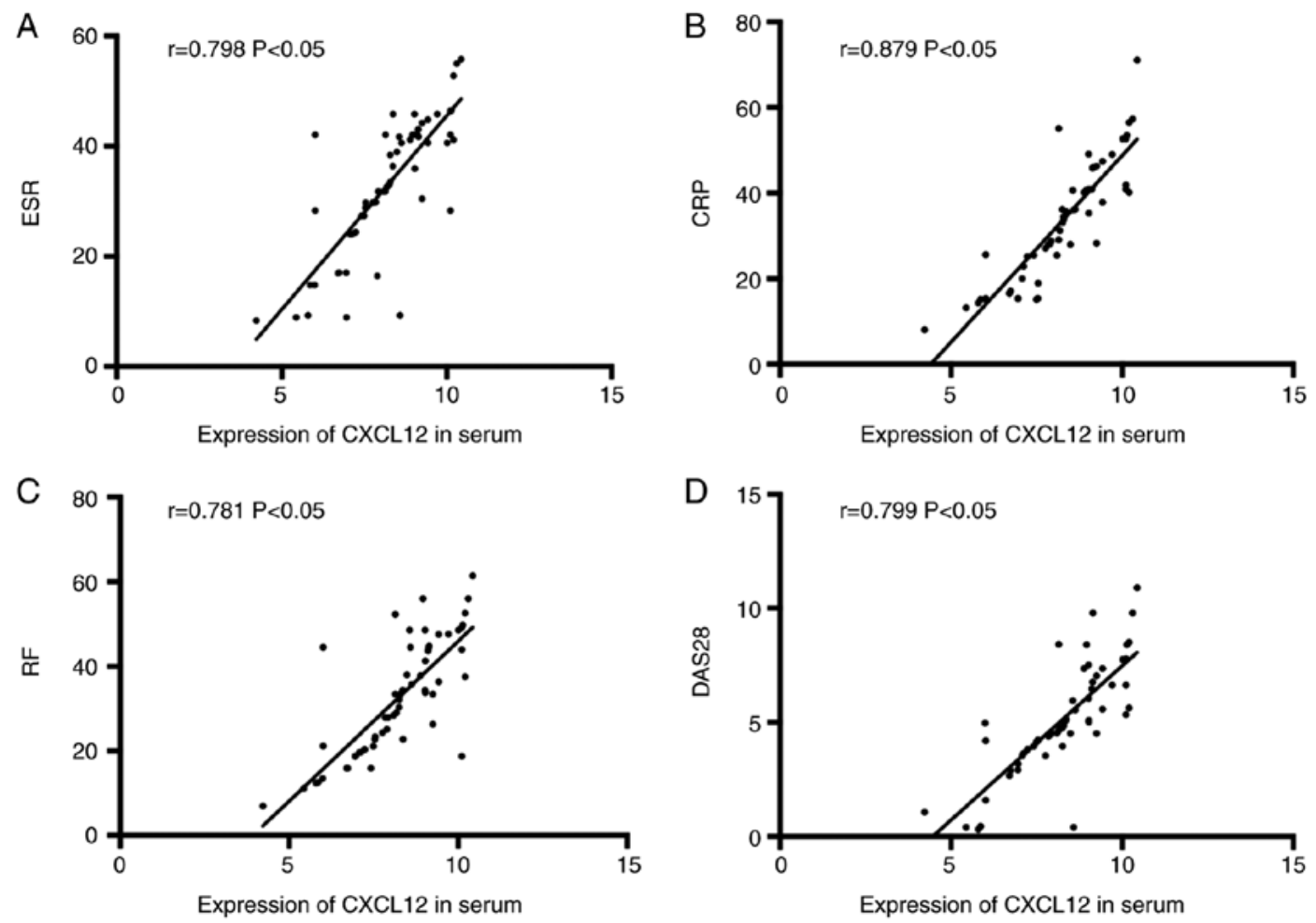

Figure 7. Correlations between serum CXCL12 expression and the ESR, CRP, RF, and DAS28 scores of patients with RA. CXCL12 expression in the serum of patients with RA was had a strong positive correlation with (A) ESR, (B) CRP, (C) RF and (D) DAS28 scores. CXCL12, C-X-C motif chemokine ligand 12; RA, rheumatoid arthritis; ESR, sedimentation rate; CRP, C-reactive protein; RF, rheumatoid factor; DAS28, disease activity score.

Table IV. CXCR4 expression levels in the serum and joint fluid of the active, remission, and control groups.

\begin{tabular}{lccccr}
\hline Factor & $\begin{array}{c}\text { Active group } \\
\mathrm{N}=32\end{array}$ & $\begin{array}{c}\text { Remission group } \\
\mathrm{N}=28\end{array}$ & $\begin{array}{c}\text { Control group } \\
\mathrm{N}=60\end{array}$ & $\mathrm{~F}$ & P-value \\
\hline Serum & $7.85 \pm 1.21$ & $3.33 \pm 1.05^{\mathrm{a}}$ & $3.05 \pm 1.1^{\mathrm{a}}$ & 156.7 & $<0.001$ \\
Joint fluid & $6.71 \pm 0.69$ & $2.41 \pm 0.57^{\mathrm{a}}$ & $2.13 \pm 0.63^{\mathrm{a}}$ & 507.2 & $<0.001$ \\
\hline
\end{tabular}

${ }^{\text {aP }}<0.05$ vs. active group. CXCR4, C-X-C motif chemokine receptor 4. F, F-test value.

Table V. CXCL12 expression levels in the serum and joint fluid of the active, remission and control groups.

\begin{tabular}{lccccr}
\hline Factor & $\begin{array}{c}\text { Active group } \\
\mathrm{N}=32\end{array}$ & $\begin{array}{c}\text { Remission group } \\
\mathrm{N}=28\end{array}$ & $\begin{array}{c}\text { Control group } \\
\mathrm{N}=60\end{array}$ & $\mathrm{~F}$ & P-value \\
\hline Serum & $10.82 \pm 1.33$ & $5.18 \pm 1.15^{\mathrm{a}}$ & $5.14 \pm 1.12^{\mathrm{a}}$ & 226.5 & $<0.001$ \\
Joint fluid & $9.46 \pm 1.59$ & $4.74 \pm 1.39^{\mathrm{a}}$ & $4.54 \pm 1.25^{\mathrm{a}}$ & 118.8 & $<0.001$ \\
\hline
\end{tabular}

${ }^{\mathrm{a}} \mathrm{P}<0.05$ vs. active group. CXCL12, C-X-C motif chemokine ligand 12. F, F-test value.

by promoting MMP secretion (37). Previous studies have demonstrated that CXCL12 and CXCR4 are closely associated with synovial cell inflammation in patients with RA $(17,38)$, but to the best of our knowledge, no previous reports have discussed the correlation between CXCL12 and CXCR4, or disease activity in patients with RA.

The present results suggested that the expression levels of CXCR4 and CXCL12 in the RA-active group were significantly higher compared with the RA-remission and control groups $(\mathrm{P}<0.05)$, but there was no significant difference between the latter two groups. Therefore, the present results indicated that the expression levels of CXCR4 and CXCL12 may be closely associated with RA pathogenesis. The correlations between CXCR4 and CXCL12 expression levels, and ESR, CRP, RF and DAS28 scores in patients with RA were also investigated. The present results suggested that CXCR4 and CXCL12 expression 


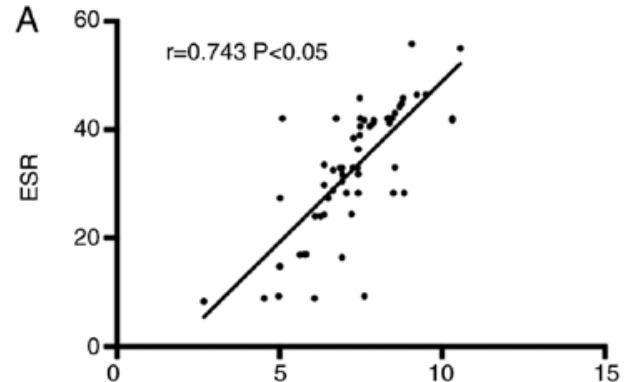

Expression of CXCL12 in synovial fluid

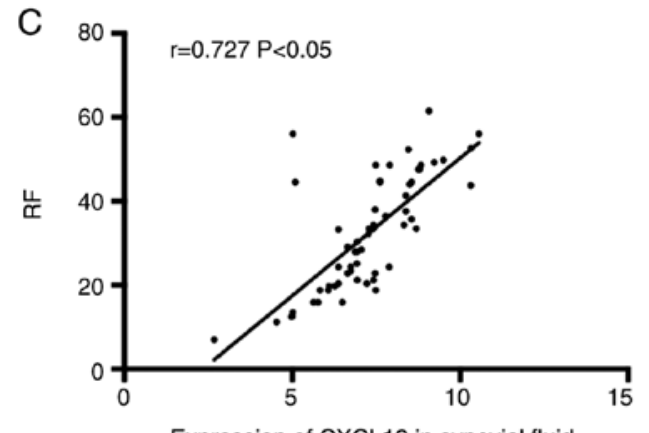

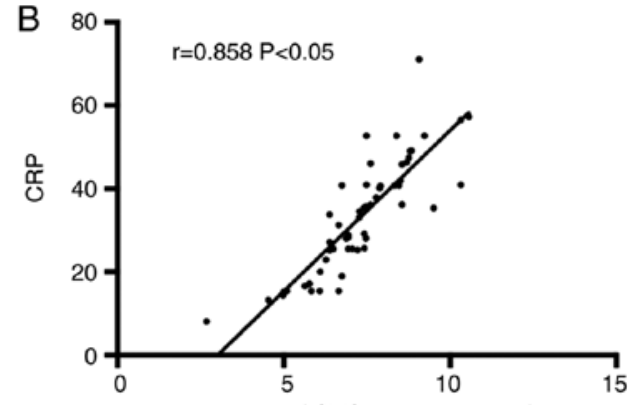

Expression of CXCL12 in synovial fluid

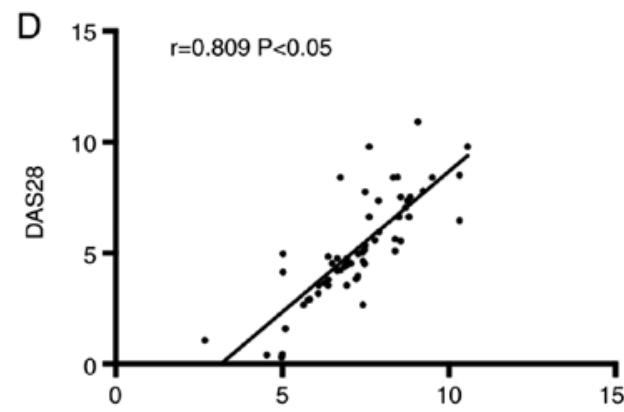

Expression of CXCL12 in synovial fluid

Figure 8. Correlations between joint fluid CXCL12 expression and the ESR, CRP, RF and DAS28 scores of patients with RA. CXCL12 expression in the joint fluid of patients with RA was had a strong positive correlation with (A) ESR, (B) CRP, (C) RF and (D) DAS28 scores. CXCL12, C-X-C motif chemokine ligand 12; RA, rheumatoid arthritis; ESR, sedimentation rate; CRP, C-reactive protein; RF, rheumatoid factor; DAS28, disease activity score.
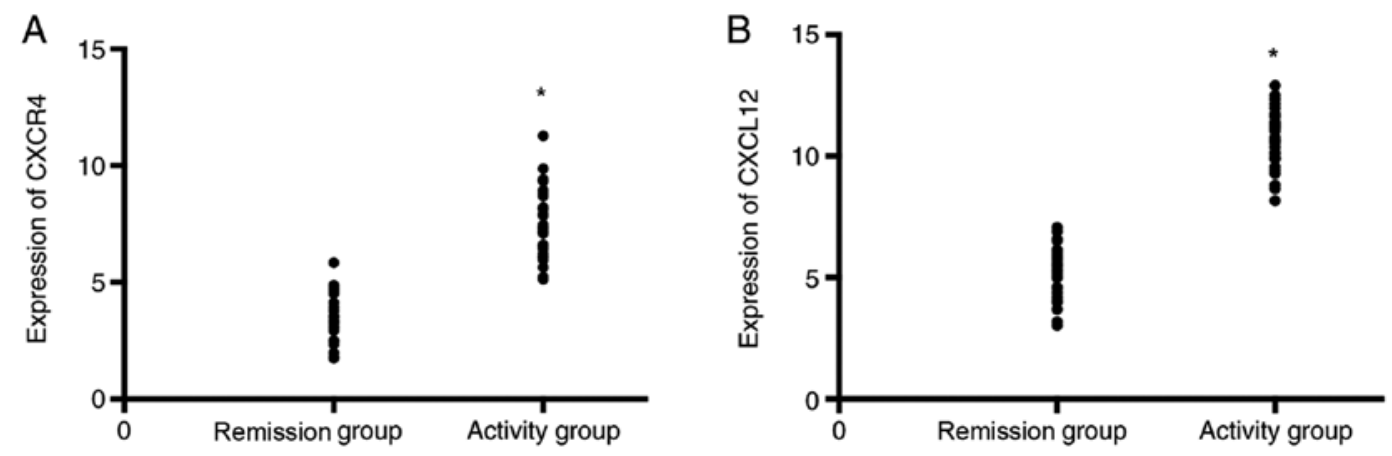

Figure 9. Correlations between the expression of CXCR4 and CXCL12 with the patient disease activity. (A) CXCR4 expression was positively correlated with the changes in RA; (B) CXCL12 expression was positively correlated with the changes in RA. CXCL12, C-X-C motif chemokine ligand 12; CXCR4; C-X-C motif chemokine receptor 4 ; RA, rheumatoid arthritis. ${ }^{*} \mathrm{P}<0.05$ vs. control group.

Table VI. Correlation between CXCR4 and CXCL12 expression in serum from the patients with RA and ESR, CRP, RF and DAS28 scores.

\begin{tabular}{llllll}
\hline & \multicolumn{2}{c}{ CXCR4 } & & \multicolumn{2}{c}{ CXCL12 } \\
\cline { 2 - 3 } \cline { 5 - 6 } Parameter & $\mathrm{r}$ & P-value & & $\mathrm{r}$ & P-value \\
\hline ESR & 0.766 & $<0.05$ & & 0.798 & $<0.05$ \\
CRP & 0.836 & $<0.05$ & & 0.879 & $<0.05$ \\
RF & 0.76 & $<0.05$ & & 0.781 & $<0.05$ \\
DAS28 & 0.751 & $<0.05$ & & 0.799 & $<0.05$ \\
\hline
\end{tabular}

CXCR4, C-X-C motif chemokine receptor 4; CXCL12; C-X-C motif chemokine ligand; RA, rheumatoid arthritis; ESR, sedimentation rate; CRP, C-reactive protein; RF, rheumatoid factor; DAS28, disease activity score.
Table VII. Correlation between CXCR4 and CXCL12 expression in joint fluid from the patients with RA and ESR, CRP, RF and DAS28 scores.

\begin{tabular}{llllll}
\hline & \multicolumn{2}{c}{ CXCR4 } & & \multicolumn{2}{c}{ CXCL12 } \\
\cline { 2 - 3 } \cline { 5 - 6 } Score & \multicolumn{1}{c}{$\mathrm{r}$} & P-value & & $\mathrm{r}$ & P-value \\
\hline ESR & 0.703 & $<0.05$ & & 0.743 & $<0.05$ \\
CRP & 0.85 & $<0.05$ & & 0.858 & $<0.05$ \\
RF & 0.788 & $<0.05$ & & 0.727 & $<0.05$ \\
DAS28 & 0.731 & $<0.05$ & & 0.809 & $<0.05$ \\
\hline
\end{tabular}

CXCR4, C-X-C motif chemokine receptor 4; CXCL12; C-X-C motif chemokine ligand; RA, rheumatoid arthritis; ESR, sedimentation rate; CRP, C-reactive protein; RF, rheumatoid factor; DAS28, disease activity score. 
levels were strongly positively correlated with ESR, CRP, RF and DAS28 scores $(\mathrm{P}<0.05)$. Therefore, these results indicated that CXCR4 and CXCL12 expression levels exhibited an effect on the disease activity of patients with RA and may be used as an index to evaluate this activity.

Previous studies have revealed that when CXCR4 and CXCL12 expression levels were increased, chemotaxis and activating effects were induced in immune cells, which leads to overactivation of immune cells and the subsequent secretion of additional inflammatory factors and their corresponding antibodies (39-41). This effect may explain the results of the present study, in which the CXCR4 and CXCL12 expression levels of patients with RA were significantly increased. Previous studies have indicated that synovial fibroblasts in patients with RA may produce high levels of CXCL12 compared with patients with osteoarthritis $(21,42)$. This is primarily due to the hypomethylation of DNA in synovial fibroblasts in patients with RA compared with patients with osteoarthritis, which may affect CXCL12 expression (43). The results from these previous studies are in line with the results of the present study. In addition, previous studies have indicated that high expression levels of CXCL12 in patients with RA are associated with a variety of pathogenic events, and that the expression of CXCL12 was positively correlated with the expression of CRP, which is consistent with results from the present study $(44,45)$. Moreover, other studies have used immunohistochemistry scoring to study synovial tissues of patients with RA and revealed that CXCL12 expression level was significantly correlated with DAS28 scores, and that the expression levels of CXCL12 and CXCR4 were closely associated with disease activity and joint destruction $(46,47)$. Previous studies indicated that CXCL12/CXCR4 expression were positively correlated with RF expression (48-50), which was consistent with the results of the present study.

In conclusion, the results of the present study suggested that CXCL12 and CXCR4 are highly expressed in patients with RA, and that these levels are positively correlated with the ESR, CRP, RF and DAS28 scores. Collectively, the results of the current study suggested that these factors may be used as indexes to evaluate disease activity in patients with RA.

However, there are some limitations to the present study. Firstly, the present results indicated that CXCL12 and CXCR4 expression levels were increased in patients with RA, but it is unknown whether the continuous increase of CXCL12 and CXCR4 expression levels were related to disease severity. Correlational analyses were conducted between the expression levels of CXCL12 and CXCR4, and the related indexes of disease activity, but further analysis was not performed. Secondly, a close relationship was revealed between CXCL12 and CXCR4 and inflammation in patients with RA, but the correlation between CXCL12 and CXCR4, and the expression of related inflammatory factors was not analyzed. Inflammatory factors serve an important role in the pathogenesis of RA and are important for the clinical evaluation of the prognosis of patients with RA (51). In addition, due to the random array method for sample selection and the limited sample size, there may be a certain deviation between the research group and the control group. The present study recruited patients with osteoarthritis as the control group, rather than healthy individuals, as it is possible to extract bone and joint fluid during the examination of patients with osteoarthritis but not healthy individuals. However, the patients with osteoarthritis did not have rheumatic diseases, thus the selection may result in some bias. Future studies will further increase the sample size and recruit a more suitable selection of individuals as controls.

\section{Acknowledgements}

Not applicable.

\section{Funding}

This work was supported by Scientific Research Project of Health Department of Hubei Province (grant no. JX6C-29).

\section{Availability of data and materials}

The datasets used and/or analyzed during the current study are available from the corresponding author on reasonable request.

\section{Authors' contributions}

LP and BW conceived the study and designed the experiments. NZ, JM and LH contributed to the data collection and performed the experiments. YY, ZZ and LW performed the data analysis and interpreted the results. LP and NZ wrote the manuscript. BW contributed to the critical revision of article. All authors read and approved the final manuscript.

\section{Ethics approval and consent to participate}

All patients and their families agreed to participate in the experiment and signed an informed consent agreement. This experiment was approved by the Hospital Ethics Committee of First People's Hospital of Jingzhou.

\section{Patient consent for publication}

Not applicable.

\section{Competing interests}

The authors declare that they have no competing interests.

\section{References}

1. Lowin T and Straub RH: Synovial fibroblasts integrate inflammatory and neuroendocrine stimuli to drive rheumatoid arthritis. Expert Rev Clin Immunol 11: 1069-1071, 2015.

2. Guo Q, Wang Y, Xu D, Nossent J, Pavlos NJ and Xu J: Rheumatoid arthritis: Pathological mechanisms and modern pharmacologic therapies. Bone Res 6: 15, 2018.

3. Lehmann J, Jüngel A, Lehmann I, Busse F, Biskop M, Saalbach A, Emmrich F and Sack U: Grafting of fibroblasts isolated from the synovial membrane of rheumatoid arthritis (RA) patients induces chronic arthritis in SCID mice-A novel model for studying the arthritogenic role of RA fibroblasts in vivo. J Autoimmun 15: 301-313, 2000.

4. Leblond A, Allanore Y and Avouac J: Targeting synovial neoangiogenesis in rheumatoid arthritis. Autoimmun Rev 16: 594-601, 2017.

5. Picerno V, Ferro F, Adinolfi A, Valentini E, Tani C and Alunno A: One year in review: The pathogenesis of rheumatoid arthritis. Clin Exp Rheumatol 33: 551-558, 2015. 
6. Andrii IR and James D: The three dimensions of somatic evolution: Integrating the role of genetic damage, life history traits and aging in carcinogenesis. Evol Appl: Mar 9, 2020 (Epub ahead of print). doi: 10.1111/eva.12947.

7. Foretz M, Guigas B and Viollet B: Understanding the glucoregulatory mechanisms of metformin in type 2 diabetes mellitus. Nat Rev Endocrinol 15: 569-589, 2019.

8. Braunersreuther V, Viviani GL, Mach F and Montecucco F: Role of cytokines and chemokines in non-alcoholic fatty liver disease. World J Gastroenterol 18: 727-735, 2012.

9. Kotrych D, Dziedziejko V, Safranow K, Drozdzik M and Pawlik A: CXCL9 and CXCL10 gene polymorphisms in patients with rheumatoid arthritis. Rheumatol Int 35: 1319-1323, 2015.

10. Antonelli A, Rotondi M, Fallahi P, Romagnani P, Ferrari SM, Barani L, Ferrannini E and Serio M: Increase of interferon-gamma-inducible CXC chemokine CXCL10 serum levels in patients with active Graves' disease, and modulation by methimazole therapy. Clin Endocrinol (Oxf) 64: 189-195, 2006.

11. Rosengren S, Kalunian KC, Kavanaugh A and Boyle DL: CXCL13 as a marker for outcome of rheumatoid arthritis: Comment on the article by Meeuwisse et al. Arthritis Rheum 63: 3646-3647, 2011.

12. Yu F, Xie Y, Wang Y, Peng ZH, Li J and Oupický D: Chloroquine-containing HPMA copolymers as polymeric inhibitors of cancer cell migration mediated by the CXCR4/SDF-1 chemokine axis. ACS Macro Lett5: 342-345, 2016.

13. Nanki T, Takada K, Komano Y, Morio T, Kanegane H, Nakajima A, Lipsky PE and Miyasaka N: Chemokine receptor expression and functional effects of chemokines on B cells: Implication in the pathogenesis of rheumatoid arthritis. Arthritis Res Ther 11: R149, 2009.

14. Brown MP, Dymock DC, Merritt KA and Trumble TN: Stromal cell-derived factor-1 (SDF-1) validation using equine serum, plasma, and synovial fluid. Osteoarthritis Cartilage 22: S71-S71, 2014.

15. Kanbe K, Takemura T, Takeuchi K, Chen Q, Takagishi K and Inoue K: Synovectomy reduces stromal-cell-derived factor-1 (SDF-1) which is involved in the destruction of cartilage in osteoarthritis and rheumatoid arthritis. J Bone Joint Surg Br 86: 296-300, 2004

16. Xiang Y, Li Y, Yang L, He Y, Jia D and Hu X: miR-142-5p as a CXCR4-targeted MicroRNA attenuates SDF-1-induced chondrocyte apoptosis and cartilage degradation via inactivating MAPK signaling pathway. Biochem Res Int 2020: 4508108 , 2020.

17. Janssens R, Struyf S and Proost P: Pathological roles of the homeostatic chemokine CXCL12. Cytokine Growth Factor Rev 44: 51-68, 2018.

18. Wang A, Guilpain P, Chong BF, Chouzenoux S, Guillevin L, Du Y, Zhou XJ, Lin F, Fairhurst AM, Boudreaux C, et al: Dysregulated expression of CXCR4/CXCL12 in subsets of patients with systemic lupus erythematosus. Arthritis Rheum 62 : 3436-3446, 2010.

19. Zhao LD, Liang D, Wu XN, Li Y, Niu JW, Zhou C, Wang L, Chen H, Zheng WJ, Fei YY, et al: Contribution and underlying mechanisms of CXCR4 overexpression in patients with systemic lupus erythematosus. Cell Mol Immunol 14: 842-849, 2017.

20. Karimabad MN, Khoramdelazad H and Hassanshahi G: Genetic variation, biological structure, sources, and fundamental parts played by CXCL12 in pathophysiology of type 1 diabetes mellitus. Int J Diabetes Dev Ctries 37: 229-239, 2017.

21. Karouzakis E, Rengel Y, Jüngel A, Kolling C, Gay RE Michel BA, Tak PP, Gay S, Neidhart M and Ospelt C: DNA methylation regulates the expression of CXCL12 in rheumatoid arthritis synovial fibroblasts. Genes Immun 12: 643-652, 2011.

22. Medina YF, Ruíz-Gaviria RE, Buitrago-Lopez A and Villota C Physical articular examination in the activity of rheumatoid arthritis: a systematic review of the literature : Systematic review of the literature regarding physical examination in rheumatoid arthritis. Clin Rheumatol 37: 1457-1464, 2018.

23. Van Thillo A, Vulsteke JB, Van Assche D, Verschueren P and De Langhe E: Physical therapy in adult inflammatory myopathy patients: A systematic review. Clin Rheumatol 38: 2039-2051, 2019.

24. Khalid S, Javad Y and Amir R: Study of erythrocyte sedimentation rate and anti-cyclic citrullinated peptide antibodies in rheumatoid arthritis. Pak Armed Forces Med J 67: 283-286, 2017

25. Varun CN, Raju R, Venkataswamy MM, Ravi V and Varambally S: Procalcitonin and C-reactive protein as peripheral inflammatory markers in antipsychotic drug-free schizophrenia patients. Asian J Psychiatr 35: 11-14, 2018.
26. Liao KP: Cardiovascular disease in patients with rheumatoid arthritis. Trends Cardiovasc Med 27: 136-140, 2017.

27. Albus E, Sinningen K, Winzer M, Thiele S, Baschant U, Hannemann A, Fantana J, Tausche AK, Wallaschofski H, Nauck M, et al: Milk fat globule-epidermal growth factor 8 (MFG-E8) is a novel anti-inflammatory factor in rheumatoid arthritis in mice and humans. J Bone Miner Res 31: 596-605, 2016.

28. Harlow L, Rosas IO, Gochuico BR, Mikuls TR, Dellaripa PF, Oddis CV and Ascherman DP: Identification of citrullinated hsp90 isoforms as novel autoantigens in rheumatoid arthritis-associated interstitial lung disease. Arthritis Rheum 65: 869-879, 2013

29. Crijns H, Vanheule V and Proost P: Targeting chemokine-glycosaminoglycan interactions to inhibit inflammation. Front Immunol 11: 483, 2020.

30. Cutolo P, Basdevant N, Bernadat G, Bachelerie F and Ha-Duong T: Interaction of chemokine receptor CXCR4 in monomeric and dimeric state with its endogenous ligand CXCL12: Coarse-grained simulations identify differences. J Biomol Struct Dyn 35: 399-412, 2017.

31. Guo F, Wang Y, Liu J, Mok SC, Xue F and Zhang W: CXCL12/CXCR4: A symbiotic bridge linking cancer cells and their stromal neighbors in oncogenic communication networks. Oncogene 35: 816-826, 2016.

32. Chung SH, Seki K, Choi BI, Kimura KB, Ito A, Fujikado N, Saijo S and Iwakura Y: CXC chemokine receptor 4 expressed in $\mathrm{T}$ cells plays an important role in the development of collagen-induced arthritis. Arthritis Res Ther 12: R188, 2010.

33. Armas-González E, Domínguez-Luis MJ, Díaz-Martín A, Arce-Franco M, Castro-Hernández J, Danelon G, Hernández-Hernández V, Bustabad-Reyes S, Cantabrana A, Uguccioni M, et al: Role of CXCL13 and CCL20 in the recruitment of B cells to inflammatory foci in chronic arthritis. Arthritis Res Ther 20: 114, 2018

34. Ding L, Amendola A, Wolf B, Bollier M, Albright J, Wang Q, Wu M, Wang X, Song H, Pedersen D, et al: Association of chemokine expression in anterior cruciate ligament deficient knee with patient characteristics: Implications for post-traumatic osteoarthritis. Knee 27: 36-44, 2020.

35. Wei F, Moore DC, Wei L, Li Y,Zhang G, Wei X, Lee JK and Chen Q: Attenuation of osteoarthritis via blockade of the SDF-1/CXCR4 signaling pathway. Arthritis Res Ther 14: R177, 2012.

36. De Buck M, Gouwy M, Struyf S, Opdenakker G and Van Damme J: The ectoenzyme-side of matrix metalloproteinases (MMPs) makes inflammation by serum amyloid $\mathrm{A}$ (SAA) and chemokines go round. Immunol Lett 205: 1-8, 2019.

37. Lin C, Liu L, Zeng C, Cui ZK, Chen Y, Lai P, Wang H, Shao Y, Zhang $\mathrm{H}$, Zhang R, et al: Activation of mTORC1 in subchondral bone preosteoblasts promotes osteoarthritis by stimulating bone sclerosis and secretion of CXCL12. Bone Res 7: 5, 2019.

38. Kircher M, Herhaus P, Schottelius M, Buck AK, Werner RA, Wester HJ, Keller U and Lapa C: CXCR4-directed theranostics in oncology and inflammation. Ann Nucl Med 32: 503-511, 2018.

39. Ren C and Duan G: The expression of SDF-1 $\alpha$ and CXCR4 in the peripheral blood patients with rheumatoid arthritis. West Chin Med J, 2018.

40. Leiblein M, Ponelies N, Johnson T, Marzi J, Kontradowitz K, Geiger E, Marzi I and Henrich D: Increased extracellular ubiquitin in surgical wound fluid provides a chemotactic signal for myeloid dendritic cells. Eur J Trauma Emerg Surg 46: 153-163, 2020.

41. Milenkovic VM, Stanton EH, Nothdurfter C, Rupprecht R and Wetzel CH: The role of chemokines in the pathophysiology of major depressive disorder. Int J Mol Sci 20: 20, 2019.

42. Karouzakis E, Gay RE, Michel BA, Gay S and Neidhart M: DNA hypomethylation in rheumatoid arthritis synovial fibroblasts. Arthritis Rheum 60: 3613-3622, 2009.

43. Doody KM, Bottini N and Firestein GS: Epigenetic alterations in rheumatoid arthritis fibroblast-like synoviocytes. Epigenomics 9: 479-492, 2017

44. Kanbe K, Takagishi K and Chen Q: Stimulation of matrix metalloprotease 3 release from human chondrocytes by the interaction of stromal cell-derived factor 1 and CXC chemokine receptor 4 . Arthritis Rheum 46: 130-137, 2002.

45. Nanki T, Hayashida K, El-Gabalawy HS, Suson S, Shi K, Girschick HJ, Yavuz S and Lipsky PE: Stromal cell-derived factor-1-CXC chemokine receptor 4 interactions play a central role in $\mathrm{CD}^{+} \mathrm{T}$ cell accumulation in rheumatoid arthritis synovium. J Immunol 165: 6590-6598, 2000. 
46. Kanbe K, Chiba J, Inoue Y, Taguchi M and Yabuki A: SDF-1 and CXCR4 in synovium are associated with disease activity and bone and joint destruction in patients with rheumatoid arthritis treated with golimumab. Mod Rheumatol 26: 46-50, 2016.

47. Diamond P, Labrinidis A, Martin SK, Farrugia AN, Gronthos S, To LB, Fujii N, O'Loughlin PD, Evdokiou A and Zannettino AC: Targeted disruption of the CXCL12/CXCR4 axis inhibits osteolysis in a murine model of myeloma-associated bone loss. J Bone Miner Res 24: 1150-1161, 2009.

48. Kamezaki K, Kikushige Y, Numata A, Miyamoto T, Takase K, Henzan H, Aoki K, Kato K, Nonami A, Kamimura T, et al: Rituximab does not compromise the mobilization and engraftment of autologous peripheral blood stem cells in diffuse-large B-cell lymphoma. Bone Marrow Transplant 39: 523-527, 2007.
49. Zou S, Zhang D, Xu Z, Wen X and Zhang Y: JMJD3 promotes the epithelial-mesenchymal transition and migration of glioma cells via the CXCL12/CXCR4 axis. Oncol Lett 18: 5930-5940, 2019.

50. Li XQ, Zhang ZL, Tan WF, Sun XJ and Ma H: Down-regulation of CXCL12/CXCR4 expression alleviates ischemia-reperfusion-induced inflammatory pain via inhibiting glial TLR4 activation in the spinal cord. PLoS One 11: e0163807, 2016.

51. McInnes IB and Schett G: Pathogenetic insights from the treatment of rheumatoid arthritis. Lancet 389: 2328-2337, 2017.

This work is licensed under a Creative Commons Attribution-NonCommercial-NoDerivatives 4.0 International (CC BY-NC-ND 4.0) License. 